\title{
Preparation and Mechanical Properties of Jute Fiber Reinforced Epoxy Composites
}

\author{
Asheesh Kumar ${ }^{1}$ and Anshuman Srivastava ${ }^{2 *}$ \\ ${ }^{1}$ Auroras Scientific Technological and Research Academy, Hyderabad, India \\ ${ }^{2}$ Department of Mechanical Engineering, SIET, Allahabad, India
}

\begin{abstract}
Nowadays, scientist and engineers working in the field of materials are too concerned with sustainability issues and environmental protection. Due to environmental friendly, bio degradability and sustainability, natural fiber composites are preferred as compared to conventional synthetic fiber based composites. An Epoxy piece and Jute fiber-epoxy composite is prepared using hand lay-up technique. For this purpose, an open type mould made of mild steel plate has been used. It is revealed that the jute epoxy composite exhibited better tensile and compressive strength. Bundle strength of fibers decreases with increase in number of fibers in a Bundle. Tensile and compressive strength increases with Jute fiber reinforcement.
\end{abstract}

Keywords: Epoxy; Biodegradable; Composites; Eco friendly

\section{Introduction}

Nowadays, scientist and engineers working in the field of materials are too concerned with sustainability issues and environmental protection. Therefore, environmental friendly, natural, recycled, or biodegradable materials are attracting lot of interest. Due to environmental friendly, bio degradability and sustainability, natural fiber composites are preferred as compared to conventional synthetic fiber based composites. They are used in diversified domains [1-5] like building materials [4-6], structural purpose, aerospace industry, automotive industry and many other applications [2-5]. Natural fibers are in considerable demand in recent years and play a key role in the emerging "green" economy. They are abundantly available, less costly, biodegradable, and easily recyclable and have low environmental impact. Lingo-cellulosic fibers have low density and sometimes process stiffness equivalent to glass fibers. Therefore, fibre reinforcement in polymeric composites is growing day by day.

Natural fibers process several technological, economic and ecological advantages. The major drawback is their high moisture absorption and poor dimensional stability, which stops their successful use in long term composite applications. Their susceptibility to moisture absorption is the main causes of their poor mechanical properties.

The mechanical properties of composite materials depend on many factors, such as fiber length, shape, size, composition, orientation and distribution, as well as volume fraction. Mechanical properties of the matrix, manufacturing techniques and bonding between fibers and matrix also play an important role. Fiberglass has been used in reinforcing polymer matrix composites since the 1930s. Kenaf, sisal, banana, cane, bamboo, jute flax, pulp, cane, wood flour, oil palm, pineapple leaf and coir are the main natural fibers used as composite reinforcement. The disadvantages include poor strength when wet and that it is also prone to microbial attack in humid climates, yellowing in sunlight [4-7].

According to Alves et al. the typical properties of jute fibers are: density: $1.5 \mathrm{~g} / \mathrm{cm}^{3}$; tensile strength: $393-773 \mathrm{MPa}$; elastic modulus: $10-30 \mathrm{GPa}$. Jute is one of the most common fibre [8]. It is cheap, and has a reasonable strength and resistance to rot. Jute is mainly used for packaging (sacks and bales). Flax fibres are strong and stiff and it can be grown in temperate climates. The fibres can also be spun to fine yarns for textile (linen). Flax and hemp are two fibres that have replaced glass fibre in a number of applications, especially in the German automotive industries.

The epoxy resins belong to the group of thermosetting resins and have a wide range of applications in the aerospace, automotive and marine industries, among others. In the preparation of composite materials reinforced with natural fibers, the hydrophilic nature of the epoxy resins becomes advantageous due to its high affinity with this type of fibers (hydrophilic nature). The versatile characteristic of epoxy and its diversity made it useful for different industrial applications such as laminated circuit board, electronic component encapsulations, surface coatings, potting, fiber reinforcement and adhesives [7-10]. However, few drawbacks such as delamination, low impact resistance, inherent brittleness, and fracture toughness behavior limit its applications in many high-performance fields. These limitations of epoxy can be overcome by incorporation and modification before their industrial applications. Currently, modified epoxy resins are extensively used in fabrication of natural fiber-reinforced composites and in making its different industrial products because of their superior mechanical, thermal and electrical properties.

The applications of NFPCs are widely growing in numerous engineering fields. The different kinds of natural fibers reinforced polymer composite have received a great importance in different automotive applications by many automotive companies such as German auto companies (Audi Group, BMW, Ford, Opel, Volkswagen, Daimler Chrysler, and Mercedes), Proton company (Malaysian national carmaker), and Cambridge industry (an auto industry in USA) [8-12]. Beside the auto industry, the applications of natural fiber composites have also been found in building and construction industry, sports, aerospace, and others, for example, panels, window frame, decking, and bicycle frame [8].

*Corresponding author: Anshuman Srivastava, Department of Mechanical Engineering, SIET, Allahabad, India, Tel: +919919701625; E-mail: anshuman0203@gmail. com

Received September 18, 2017; Accepted September 28, 2017; Published October 06, 2017

Citation: Kumar A, Srivastava A (2017) Preparation and Mechanical Properties of Jute Fiber Reinforced Epoxy Composites. Ind Eng Manage 6: 234 doi:10.4172/2169-0316.1000234

Copyright: ( 2017 Kumar A, et al. This is an open-access article distributed under the terms of the Creative Commons Attribution License, which permits unrestricted use, distribution, and reproduction in any medium, provided the original author and source are credited. 
Citation: Kumar A, Srivastava A (2017) Preparation and Mechanical Properties of Jute Fiber Reinforced Epoxy Composites. Ind Eng Manage 6: 234. doi:10.4172/2169-0316.1000234

Page 2 of 4

There are considerable suggestions for the natural fibers that can be implemented in order to enhance their mechanical properties. Once the base structures are made strong, the polymers can be easily strengthened and improved [7-9]. There are number of aspects that effects the performance of composites are the following; (a) orientation of fiber, (b) strength of fibers, (c) physical properties of fibers, (d) interfacial adhesion property of fibers and many more [8-13]. NFPCs are such composites whose mechanical efficiency is dependent upon the interface provided by fiber-matrix along with the stress transfer function in which stress is transferred to fiber from matrix. This has been reported by many investigators in several researches. Such features play a constitutive role in the determination of NFPCs mechanical properties. Mechanical properties of PLA, epoxy, PP, and polyester matrices can be affected by reinforcing different types of natural fibers [14-18].

\section{Experimental Section}

\section{Fabrication of epoxy piece and jute fibre reinforced composites}

Types of specimens fabricated:

i. Epoxy piece

ii. Jute fibre reinforced composite.

An Epoxy piece and Jute fibre-epoxy composite is prepared using hand lay-up technique. For this purpose, an open type mould made of mild steel plate $(600 \mathrm{~mm}$ long $\times 300 \mathrm{~mm}$ wide $\times 27 \mathrm{~mm}$ thick $)$ has been used. For that a Mylar sheet is placed on the lower part of mould for a good surface finish and easy withdrawal of composite from the mould in addition to it wax is also used to cover the surface of Mylar sheet for easy withdrawal of composite from Mylar sheet. Then the epoxy resin (Araldite AY103) has been layered on the mould (1-1.5 mm) thickness and jute fibres placed uni-directionally on it. The weights are hung on both sides to maintain tension in the fibres. After removing the entrapped air with the help of metal roller rolled on the layer, thereafter another layer of epoxy resin has been poured on the mould. Then upper part of mould is placed on side plates, which is placed on both side of lower part of mould. Then the cover is put over the mould and left for 48 hour for curing. After 48 hours it is removed from the mould and then test specimens of required dimensions are cut from the fabricated piece. The Jute composite pieces produced are single ply having thickness between 4-5 $\mathrm{mm}$. In this way we prepared the specimen of size $(400 \mathrm{~mm} \times 250 \mathrm{~mm} \times 3 \mathrm{~mm})$. The composite produced single ply 3 $\mathrm{mm}$ thickness and is shown in Figure 1.

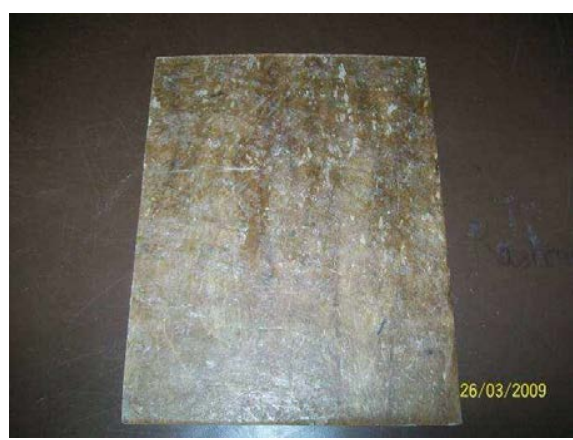

Figure 1: Jute fibre-epoxy composite.

\section{Result and Discussion}

\section{Jute fibre}

Characterization of Jute fibre in natural condition

Physical and mechanical properties,

Properties Jute fibre,

Mean fibre diameter $(\mathrm{mm})=0.07-0.08$,

Density $\left(\mathrm{gm} / \mathrm{cm}^{3}\right)=1.3-1.4$,

Elongation at failure $(\%)=3.6-4.2$.

Characterization of bundle of jute fibre in dry condition

Natural fibre bundle, straight configuration shows linear behaviour up to some portion of the curve and then becomes non-linear at higher loads.

Mechanical properties - Tensile testing in straight configuration of bundle of 50 and 100 Jute fibre has been found in the range of 1324.15$1394.12 \mathrm{Kg} / \mathrm{cm}^{2}$ (Table 1).

\section{Tensile test of epoxy and jute fibre reinforced composites}

This test is performed on Hounsfield Tensometer. Range of scale selected is $0-500 \mathrm{kgf}(0-2452.5 \mathrm{~N})$. The specimen is prepared in accordance with ASTM D 3039-76 standard $(150 \mathrm{~mm} \times 30 \mathrm{~mm} \times 3$ $\mathrm{mm}$ ) and is shown in Figure 2.

Where A is cross-sectional area;

Following are the details of the specimen:

i. Length $=150 \mathrm{~mm}$,

ii. Width $=30 \mathrm{~mm}$,

\begin{tabular}{|l|l|l|l|l|}
\hline Fibers Name & $\begin{array}{l}\text { Density } \\
\left(\mathbf{g} / \mathbf{c m}^{\mathbf{3}} \mathbf{)}\right.\end{array}$ & $\begin{array}{l}\text { Elongation } \\
\mathbf{( \% )}\end{array}$ & $\begin{array}{l}\text { Tensile } \\
\text { Strength } \\
\mathbf{( M p a )}\end{array}$ & $\begin{array}{l}\text { Young's } \\
\text { modulus } \\
\mathbf{( G p a )}\end{array}$ \\
\hline Jute & 1.3 & $3.5-4.5$ & $393-723$ & 26.5 \\
\hline Hemp & - & 1.6 & 690 & - \\
\hline Ramie & - & $3.6-3.8$ & $100-938$ & $61.4-128$ \\
\hline Sisal & 1.5 & $2.0-2.5$ & $511-635$ & $94.0-22.0$ \\
\hline Coir & 1.2 & 30 & 125 & $40-6.0$ \\
\hline Palmyra fiber & 0.7 & $8-24$ & $49.05-189.53$ & 7.78 \\
\hline Viscose (cord) & - & 11.4 & 593 & 11 \\
\hline Soft wood kraft & 1.5 & - & 1000 & 40 \\
\hline E-glass & 2.5 & 2.5 & $2000-3500$ & 70.0 \\
\hline S-glass & 2.5 & 2.8 & 4570 & 83.0 \\
\hline Aramide & 1.4 & $3.3-3.7$ & $3000-3150$ & $63.0-67.0$ \\
\hline Carbon & 1.4 & $1.4-1.8$ & 4000 & $230-240$ \\
\hline Cotton & $1.5-1.6$ & $7.0-8.0$ & $287-597$ & $5.5-12.6$ \\
\hline
\end{tabular}

Table 1: Comparison of Jute fibre properties with other natural fibres.

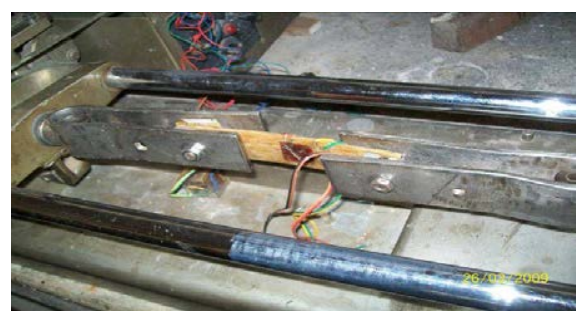

Figure 2: Test specimen mounted on Hounsfield Tensometer. 
iii. Thickness $=3 \mathrm{~mm}$,

iv. Cross-sectional area $=30 \times 3=90 \mathrm{~mm}^{2}$.

To record strains, a three-element rectangular strain gauge rosette is mounted on the specimen as shown in the Figure 2. Strains are measured with the help of strain indicator. The strain gauge is mounted on the specimen, along the fibre direction taken $\mathrm{X}$-axis, perpendicular to the fibre direction taken $\mathrm{Y}$-axis and on the $45^{\circ}$ taken $\mathrm{Z}$-axis for shear strain.

Specifications of strain gauge are:

i. Type: BKCT - 3R,

ii. Resistance: $119.0 \pm 0.5 \mathrm{ohm}$,

iii. Gauge length: $3 \mathrm{~mm}$,

iv. Gauge factor: $1.96 \pm 0.2$ (Figure 3).

From the tensile test it was found that with the composites exhibit better tensile strength in comparison to epoxy. It shows that composite offer greater resistance to externally applied load. As the fibres are laid uni-directionally, it exhibit good strength in longitudinal direction in comparison to transverse direction.

\section{Compression test of epoxy and jute fibre reinforced composite}

Compression test for U/D jute fibre-epoxy composite is performed on Hounsfield Tensometer. The load scale choosen is of $0-2000 \mathrm{~kg}$ $(19.62 \mathrm{kN})$. The specimen size according to ASTM D 695-80 Standard is shown in Figure 4.
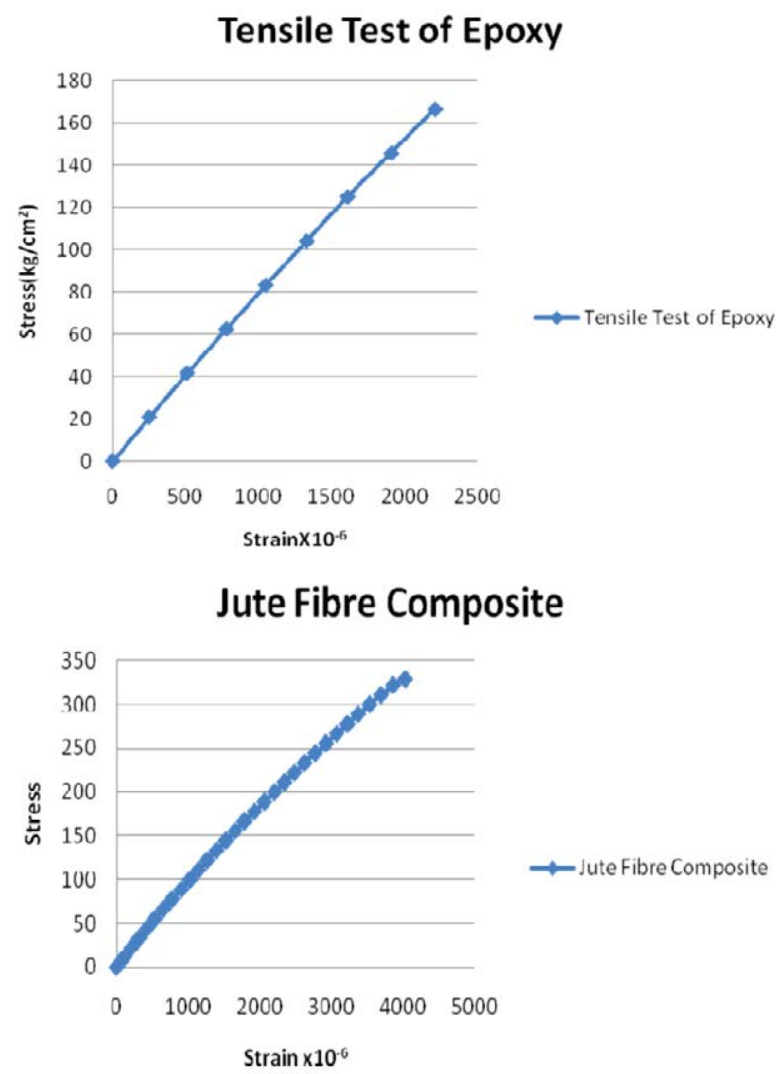

Figure 3: Stress-strain diagram for Epoxy and composite.
i. Length $=25 \mathrm{~mm}$
ii. Width $=25 \mathrm{~mm}$
iii. Thickness $=3 \mathrm{~mm}$
iv. Cross-sectional area $=25 \times 25=625 \mathrm{~mm}^{2}$.

To record strains, a three-element rectangular strain gauge rosette is mounted on the specimen as shown in the Figure 4. Strains are measured with the help of strain indicator. The strain gauge is mounted on the specimen, along the fibre direction taken $\mathrm{X}$-axis, perpendicular to the fibre direction taken $\mathrm{Y}$-axis and on the $45^{\circ}$ taken $\mathrm{Z}$-axis for shear strain (Figure 5).

Compression test indicates that the composites are better in compressive strength in comparison to epoxy. Reason for the increase in the compressive strength of composites can be attributed to the bonding between fibre and matrix.

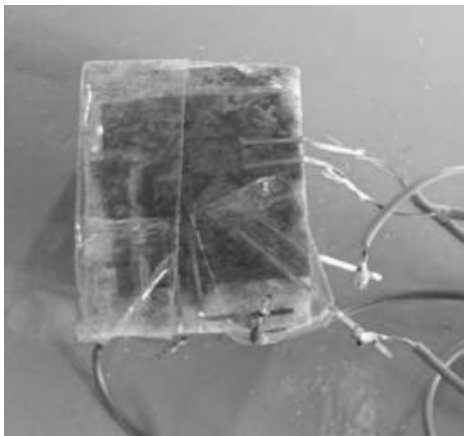

Figure 4: Composite specimen for compression test.

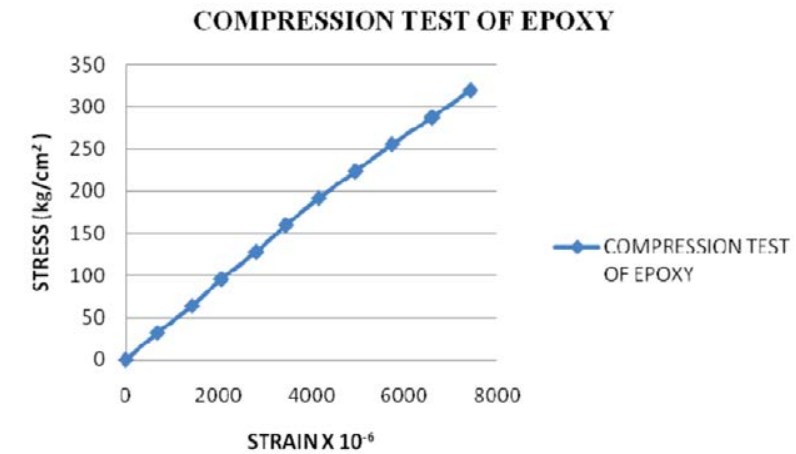

Jute Fibre Composite

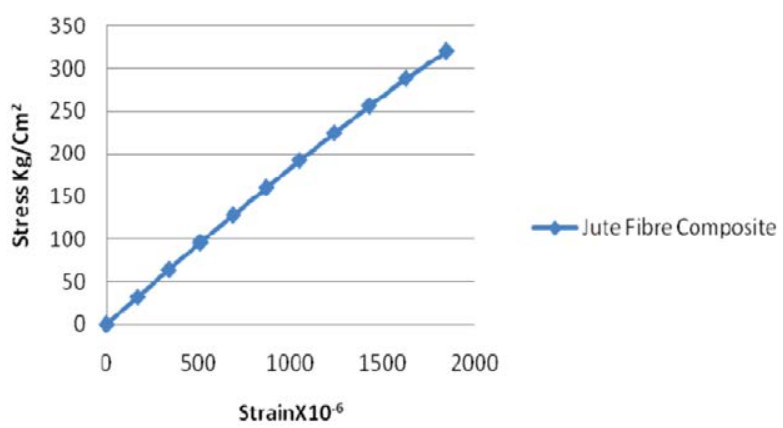

Figure 5: Stress-strain diagram for compression test for Epoxy and composite. 
Citation: Kumar A, Srivastava A (2017) Preparation and Mechanical Properties of Jute Fiber Reinforced Epoxy Composites. Ind Eng Manage 6: 234. doi:10.4172/2169-0316.1000234

\section{Failure modes of composite}

Composites material usually fails in following modes.

\section{In tension}
a) Breaking of fibres,
b) Cracking/deformation of matrix,
c) Shearing of matrix,
d) Delamination of lamina,
e) Debonding of fibre from matrix,
f) Fibre pull out.

\section{In compression}
a) Buckling of fibre,
b) Crushing of matrix,
c) Shearing of matrix,
d) Crushing of lamina,
e) Shearing of laminate.

\section{Conclusion}

After investigating the properties of Jute fibre reinforced Epoxy composite the following conclusion is drawn. From the above results, it revealed that the jute epoxy exhibited better tensile and compressive strength. Bundle strength of fibres decreases with increase in number of fibres in a Bundle. Tensile strength increases with Jute fibre reinforcement. Bending strength increases with increase in percentage of Jute fibre. Compressive strength increases with increase in percentage of Jute fibre. Impact strength has no noticeable change after addition of fibre. These types of composites can be very useful for construction purpose, partition boards, wall, floor, window and door frames, roof tiles, mobile or pre-fabricated buildings which can be used in times of natural calamities such as floods, cyclones, earthquakes, etc.

\section{References}

1. Kabir MM, Wang H, Lau KT, Cardona F (2012) Chemical treatments on plantbased natural fibre reinforced polymer composites: An overview. Composites Part B: Engineering 43: 2883-2892.

2. John MJ, Thomas S (2008) Biofibres and biocomposites. Carbohydrate Polymers 71 : 343-364.

3. Hapuarachchi TD, Peijs T (2010) Multiwalled carbon nanotubes and sepiolite nanoclays as flame retardants for polylactide and its natural fibre reinforced composites. Composites Part A: Applied Science and Manufacturing 41: 954 963.

4. Xin X, Xu CG, Qing LF (2007) Friction properties of sisal fibre reinforced resin brake composites. Wear 262: 736-741.

5. Sreekala MS, Kumaran MG, Thomas $S$ (2001) Stress relaxation behaviour in oil palm fibres. Materials Letters 50: 263-273.

6. Faruk O, Bledzki AK, Fink HP, Sain M (2012) Biocomposites reinforced with natural fibers: 2000-2010. Progress in polymer science 37: 1552-1596.

7. Shalwan A, Yousif BF (2013) In state of art: mechanical and tribological behaviour of polymeric composites based on natural fibres. Materials \& Design 48: $14-24$.

8. Shinoj S, Visvanathan R, Panigrahi S, Kochubabu M (2011) Oil palm fibe (OPF) and its composites: A review. Industrial Crops and Products 33: 7-22.

9. Ku H, Wang H, Pattarachaiyakoop N, Trada M (2011) A review on the tensile properties of natural fiber reinforced polymer composites. Composites Part B: Engineering 42: 856-873.
10. Arrakhiz FZ, El Achaby M, Malha M, Bensalah MO, Fassi-Fehri O, et al. (2013) Mechanical and thermal properties of natural fibers reinforced polymer composites: Doum/low density polyethylene. Materials \& Design 43: 200-205.

11. Srivastava A, Maurya M (2015) Preparation and mechanical characterization of epoxy based composite developed by biowaste material. IJRET: International Journal of Research In Engineering And Technology 4

12. Di Bella G, Fiore V, Galtieri G, Borsellino C, Valenza A (2014) Effects of natura fibres reinforcement in lime plasters (kenaf and sisal vs. Polypropylene). Construction and Building Materials 58: 159-165.

13. Izani MN, Paridah MT, Anwar UMK, Nor MM, H'ng PS (2013) Effects of fiber treatment on morphology, tensile and thermogravimetric analysis of oil palm empty fruit bunches fibers. Composites Part B: Engineering 45: 1251-1257.

14. Mishra V, Srivastava A (2014) Epoxy/Wood Apple Shell Particulate Composite With Improved Mechanical Properties. Int. Journal of Engineering Research and Applications 4: 142-145.

15. Tawakkal IS, Cran MJ, Bigger SW (2014) Effect of kenaf fibre loading and thymol concentration on the mechanical and thermal properties of PLA/kenaf/ thymol composites. Industrial Crops and Products 61: 74-83.

16. Jayamani E, Hamdan S, Rahman MR, Bakri MKB (2014) Comparative study of dielectric properties of hybrid natural fiber composites. Procedia Engineering 97: $536-544$

17. Srivastava A, Maiti P, Kumar D, Parkash O (2014) Mechanical and dielectric properties of CaCu3Ti4 $\mathrm{O} 12$ and $\mathrm{La}$ doped CaCu3Ti4O12 poly (vinylidene fluoride) composites. Composites Science and Technology 93: 83-89.

18. Eng CC, Ibrahim NA, Zainuddin N, Ariffin H, Yunus WMZW (2014) Impact strength and flexural properties enhancement of methacrylate silane treated oil palm mesocarp fiber reinforced biodegradable hybrid composites. The Scientific World Journal. 